\title{
Social engineering of the Internet in developing areas
}

\author{
Wesley Shrum
}

Louisiana State University, Department of Sociology, Baton Rouge, Louisiana 70803 USA, Tel. 225-578-5311, Fax. 225-578-5102

shrum@lsu.edu; http://worldsci.net

Abstract: Communication among researchers is fundamental to the development of knowledge in both developed and developing areas. Internet connectivity is now a precondition for participation in research communication. Establishing reliable and efficient connectivity at reasonable bandwidth is a task that is assumed to be relatively easy and straightforward in developed countries, but is surprisingly difficult in developing areas. Our project has sought to establish connectivity for university departments and government research institutes in India, Ghana, and Kenya but has yet to experience an unqualified 'success' for a variety of institutional and relational reasons. The concept of 'reagency' is used in preference to 'development' to explain the priority of personal relations introducing significant constraints that must be faced directly to establish connectivity in developing areas.

Key words: Africa, developing areas, Internet, science, technology 


\section{ENGINEERING THE KNOWLEDGE SOCIETY}

"Engineering the Knowledge Society" is a large and beautiful concept that resonates with-indeed, underlies-the World Summit on the Information Society. My topic today centres on the Internet in developing areas, particularly in the educational and research sectors, and the ways in which we need to be particularly attentive to the character of the connectivity initiatives that are undertaken under the rubric of the "digital divide". If we are not careful, they will fall prey to the same problems of face-to-face interaction between donors and recipients that have characterised prior initiatives. What I want to emphasise before discussing our Louisiana Internet Project is the close correspondence between the idea of "engineering the knowledge society" and the approach generally taken by those in the field of "STS". (The Louisiana Internet Project is sometimes referred to as the World Science Project but that is a misnomer-it is because the domain name (http://worldsci.net) is a placeholder web page for a follow up event now being planned for the Tunis phase of the Summit.)

\section{SCIENCE AND TECHNOLOGY STUDIES}

"STS" once meant "Science, Technology, and Society" and now means, for many of us in this field "Science and Technology Studies". This is an interdisciplinary field with its own journals (Science, Technology, and Human Values; Social Studies of Science), professional society (the Society for Social Studies of Science), annual meetings, handbooks, and all the other apparatus one expects from a scholarly area. The reason that I bring this up is that this change of name-one should properly say this ambiguity in the meaning of the initials "STS"-reflects a long term shift in the way that scholars have come to view technology: not as a separate entity but as inextricably interwoven in the fabric of social organisation. Ideas that Technology Affects Society, or that Society Shapes Technology have become less significant than the notion of the "seamless web" in which things and people and social formations are tied together in networks or dynamic assemblages. That shift represents a growing awareness that technology is socially constructed, an awareness that many would equate with social engineering. The guiding idea here at our Geneva meeting is that ICT cannot be seen as a separate entity-and that is the close correspondence with the core theoretical and empirical concerns of STS. 


\section{RESEARCH COLLABORATIONS}

Now may I qualify this in an important way-when we go on to say that the application of ICT has to be engineered, this must be viewed as the kind of interactive social engineering that is represented by research collaborations involving multiple countries, multiple organisations, and multiple points of reference. It would not be correct to view this kind of engineering as a direct-from-headquarters mandate to create a new product or design a new structure. The Internet is a collaboration in two respects:

1. As an innovative and powerful set of technologies, computer-mediated communication changes the conditions of physical presence and time delay that have characterised most forms of human interaction;

2. As an initiative focusing on connectivity, the Internet is the greatest collaboration the world has ever known, "greatest" both in the sense of potential benefits and potential danger.

That structure is often called decentralised but we must be careful when we apply that term to global diffusions such as the connectivity initiative that is the most obvious reference of "engineering the knowledge society". The connectivity initiative is no more decentralised than initiatives on poverty, education, agriculture, health, and environmental sustainability.

\section{DIGITAL DIVIDE IN EDUCATIONAL AND RESEARCH SECTORS}

After about ten years of work in the developing world, it became obvious to me that the digital divide is nowhere more evident than in the educational and research sectors themselves. That is ironic, of course, since it was within those organisations that most of the primary innovations occurred in the developed world, innovations that together became the Internet. Yet communication among researchers is fundamental to the development of knowledge in both developed and developing areas. Internet connectivity is now a precondition for participation in many forms of social involvementlike applying to my university for graduate work. Among these is research collaboration. Establishing reliable and efficient connectivity at reasonable bandwidth is a task that is assumed to be relatively easy and straightforward in developed countries, but is surprisingly difficult in developing areas. Our project has sought to establish connectivity for university departments and government research institutes in India, Ghana, and Kenya but has yet to experience an unqualified "success" for a variety of institutional and relational reasons. What we have discovered is the conceptual poverty of the 
notion of "development" as an adequate description for the processes we have witnessed since beginning our own connectivity project. We now use the concept of "reagency" to refer to the priority of personal relations introducing significant constraints that must be faced directly to establish connectivity in developing areas.

For the sake of perfect honesty, I must tell you that I am a sociologist and my primary teaching interest has been contemporary theory for precisely the same period that I have been working in the developing world. Sociologists are usually thought to be abstract, while engineers are concrete and practical. Indeed, one of the most common criticisms I have heard about sociologists - not to mention theorists--is that they are not practical. They fail to confront the real problems. They refuse to get down and dirty their hands. That could be true-but let me narrate to you exactly what has happened to our project and why I say to you now that most of the talk about closing the digital divide is just abstract and theoretical. Here I am talking about digital inclusion for the research and educational sectors of subSaharan Africa.

\section{DIGITAL INCLUSION}

Before you can talk about digital inclusion you must be prepared to do two things. One is to confront the legacy of "development", that is, the ways in which initiatives, programs, and projects have been imported by donors (NGOs, multilateral and bilateral aid agencies). The second is to do some work-good, old-fashioned work-where you measure distances, and get bids, and buy cables and connectors, and assess the relative merits of wireless and wired, and get up on top of rooftops and water towers and find a line of sight. Then you have got to supervise the whole thing and make sure that the work is done. I ask you, is that the work of a theoretical sociologist? I hope so. But if not, then I am happy to be a social engineer.

\section{LOUISIANA INTERNET PROJECT}

What is now the Louisiana Internet Project began in the early 1990s and focused on the production of knowledge in developing areas in the fields of agriculture and environment. After receiving funding from the Dutch Advisory Council on Scientific Research for Development Problems (RAWOO), the project collected a large amount of data in 1994 from professionals in universities, government research institutes, and NGOs in Kenya, Ghana, and the Indian state of Kerala. The focus was not the 
Internet-indeed, the word was not much heard at that time-but it did generate a fairly elaborate set of data on communication and other types of linkages between individuals and organisations, both within and outside of these locations.

There are three basic findings from this 1994 study that are worth emphasising in trying to engineer the knowledge society in the developing world. First, we used data on several hundred knowledge workers in Kerala, Ghana, and Kenya to examine the character and location of their professional contacts. What we found caused us to redraw our picture of "isolated" researchers in the Third World. They are not "isolated", but rather their social ties were primarily local rather than international. Since most human populations throughout human history have had precisely this local character, it is not surprising. The scientists we studied had numerous social and professional ties but they were with others in their national research system.

The second major finding was the negative relationship between local and foreign professional networks. Put simply, there was a tendency for those with more ties to the developed world to have fewer local ties, and for those who had more extensive domestic contacts to have fewer linkages outside-that is, in the international arena. Whether or not that is surprising depends on one's preconception about the nature of work involving the creation of knowledge but it does have one fairly disturbing implication: that in the pre-Internet era the costs of communication (more broadly, relational involvement) meant that professional networks were a zero-sum game. It is only with great difficulty that one can have both foreign and local ties.

The third major finding was that the pattern of professional linkages to those in the developed world did not display any large differences for those who were and those who were not educated in the developed world. That is, knowledge workers educated in the U.S. and Europe had no greater contact with Western scientists than those educated locally. This finding seemed surprising to everyone-including me-and the meaning seemed fairly clear. Those who went abroad were quickly "reabsorbed" into the local system. Ask yourself: how often do you maintain contact with those you met in graduate school-your professors and colleagues? Our respondents in Africa and Asia did not maintain any kind of regular contact with others they had met or worked with during their postgraduate training.

\section{CONNECTIVITY}

As I was working on these issues back in the mid-1990s, the International Council for Science (ICSU) formed a Committee for Capacity 
Building in Science, immediately identifying one of its three core issues as the "problem of isolation". While I am all for greater attention to knowledge processes in developing areas, I am reluctant to use that particular phraseology, given that professionals do not have any obvious deficit in the number of their contacts. Still, the promise of the Internet to me was not that "isolation" would be "cured" through connectivity. It was that the negative relationship between internal and external linkages might be changed. Let me reiterate this point in a slightly different way. That the Internet might make it possible for knowledge workers in developing areas to collaborate with those in the developed world is not the central issue-such collaborations have occurred for a long time. The potential is that this technology might allow an increase in all forms of communication-both domestic and international. Connectivity rapidly became one of the most important-if not the most important initiative in science and technology for development. We were not unhappy to have one of the best data sets in existence for the study of non-Internet era communication in the developing world. I only wish I could make a plausible case that I had thought of that in advance!

\section{FOLLOW-UP STUDY}

What happened next was that we began to design a follow up study of the ways that knowledge workers used the Internet, a study that would examine its effects on international collaboration, the maintenance of professional ties forged during graduate training, the activation of what sociologists call "weak ties", the distribution of types of relationships across career levels, and, of course, the degree to which these patterns vary by country and sector. We had always considered Ghana to be at the lower end of the developmental scale for our three locations, with Kenya in the middle, and Kerala - with its high level of literacy and emphasis on education-to be on the top.

During the planning phase in mid-1999 through early 2000 we found that most of the university faculties and research institutes did not have connectivity to the Internet-or had such sporadic, limited, and high cost connections that they did not function in any significant way. What we concluded was that we had to provide the Internet in order to study the Internet. These last three years have been, truly, an experience for mebecause I have become a mini-development agency during the course of trying to examine what were originally just some interesting sociological questions. A half million dollars can cause you a lot of trouble when you have to give it away. 
This simple fact is something that all aid agencies and NGOs know, but because they are generally not in the business of studying themselves, because they tend to have more money than I do, and because they are involved in a large portfolio of projects, they cannot spend a great deal of time reflecting on its consequences. At the technological level, the Louisiana Internet Project is trying to do some fairly simple things. We are not doing anything as complicated as, say, building a bridge. The only bridge we are building is to the Internet. It is a matter of great excitement, of great potential, and it is worth learning how to do it. Cabling a building or configuring a wireless network for Internet access is a necessary condition for digital inclusion. Of course, it does not in itself reduce the digital divide without a wide range of other elements, elements of organisation, elements of practice and habit. But what I am emphasising here is money, resources, support. Getting practical things done takes money. I have a grant with a lot of money and I cannot spend it. That seemed strange to me at the outsetbut it was a function of wanting to be assured, at some reasonable level that I cannot define, that the money would be well spent. But now it seems less strange, in light of the conditions of interactions between donors and recipients of aid that have persisted since World War II. In those terms, the connectivity initiative is simply another in a long line of Western concepts that have waxed and waned in importance, or in the more cynical view of one of my 1994 informants:

"It will be another white elephant. The donors will come in and try to establish electronic links, then leave and not support the system. It's not that important.

I continue to think it is important-especially to those professionals engaged in the business of producing knowledge. So why is it so difficult to perform these basic tasks of cabling and connectivity that are actually the preconditions of getting on with collaborative activity? What I have to say next is spoken in a code, but $I$ think the listeners in this room are able to crack it. In many cases the recipients of aid are better at receiving money than development projects are at giving it. That fact is at the root of my statement at the beginning of this talk, that our project has yet to experience an unqualified success for institutional and relational reasons. The institutions of development, embedded in a set of inter-organisational relations and social practices, have conspired to make it difficult to establish the connectivity that must first occur as a precondition to reducing the digital divide. " 


\section{CONCLUSION}

Let me end with an illustration, a concept, and a recommendation. In the cases I am familiar with (Ghana, Kenya, and India) the actual amount of money that is really necessary to network a group of computers in offices to a properly configured server is not very much. However, when you begin to consider the logistics involved in providing the necessary amount of money for the necessary services you begin to see the problems. You cannot simply touch down in a country and go to the first store that you find. You have a limited amount of time in a country so you must work fast. You may find that payment is required before the work is done-not part now, part later. Vendors know that non-payment is very common so they do not want to do the work before the money is assured. Some vendors will flat-out refuse consideration of any job that is not backed by foreign money-if it is a Kenyan project, then they will want to be assured that the money is actually from the USAID, for instance, before going forward. On the other side of the equation, the customers desiring the connectivity do not have a very high opinion of most vendors - they often go out of business or disappear before the work is done-so there is a great reluctance to go forward unless it is with someone else's money. In eastern Kenya, together with some excellent colleagues and assistance, we cabled a building so that researchers at an agricultural institute could have a desktop connection. It cost approximately $\$ 2000$, with one individual from the station providing most of the labour himself. That took more than one year-a job that our colleagues in the U.S. kept saying should be done in a couple of days. Let me give another example. At a nearby institute the cost of the materials and installation was given to me at $\$ 95,000$. This is why the ideas of participation, buy-in, and cost-sharing became important. But I submit that those are not enough.

The problem has more to do with the priority of personal face-to-face relationships in developing areas, and particularly the relationship between face-to-face contact and electronic communication. In the example of the high bid, the key fact is that we were unable to extract the bid from the contractor until after we had left the country and email did not prove sufficient to clarify the relatively limited project requirements. We were perceived as "donors with deep pockets", in the words of one of our local collaborators. We have become enmeshed in the institution of development--but we are not developing anything. This is why we have rejected the concept of "development" and turned to "reagency". When organisational representatives from afar alight in countries bringing resources in the service of international initiatives, they take part in or bring about a reaction. We are not really interested in the representatives themselves but rather these reactions-the chains of events that occur as 
resources enter a matrix of personal relations in an area of scarcity. Our general thesis is that the Internet has a potential that prior initiatives did not have-because the intermittent, computer-mediated interactions can maintain relationships and projects after the donor has left, and bring about the non-immigratory friendships that can and do have a positive impact on knowledge, on social network formation, and on the success of projects.

This process of reagency leads me to the recommendation. The very best way of understanding the problems is to follow the old-fashioned advice: try this yourself. Pick a place in Africa, in Latin America, in Asia, and get it connected to the Internet. At best, you will establish a potential. At worst, you will fail, but you will understand-and you will have participated in the greatest collaboration the world has ever known.

\section{BIOGRAPHY}

Wesley Shrum has been Professor of Sociology at Louisiana State University since 1982. Since 1987 he has been Secretary of the Society for Social Studies of Science, an international and interdisciplinary association for the study of science and technology with over 1200 members worldwide. The basic aims of the society are to bring together those interested in understanding the social dimensions of science, technology, engineering, and medicine through annual meetings and publications.

Professor Shrum has been studying the social networks and communication practices of scientists and engineers since the 1970s. His first book, Organized Technology: Networks and Innovation in Technical Systems (Purdue University Press, 1985), examined the social networks of researchers involved in nuclear waste and solar photovoltaic research in the U.S. In the early 1990s his primary interest shifted to the developing world, still focused on communication and collaboration in the research process. For the past ten years he has focused on Ghana, Kenya, and the state of Kerala in south-western India. In 1994, Prof. Shrum directed comprehensive studies of the research institutions in these areas. His current studies examine the impact of the Internet on communication patterns with particular emphasis on international relations. 